\title{
La fase escrita de la etapa intermedia en el proceso penal acusatorio
}

\author{
The written phase of the intermediate stage in the accusatory criminal process
}

\author{
Javier Sánchez-Lazcano ${ }^{a}$, Roberto Wesley Zapata $^{b}$, Martha Gaona $^{c}$
}

\begin{abstract}
:
The intermediate stage in the accusatory criminal process is constituted by two phases: the written and oral, in this work the written phase is approached, for this purpose it is explained what it consists of, the importance and requirements of the indictment, it becomes special reference to the principle of factual congruence and its relation to the formulation of imputation and the sentence; the forms of authorship and participation and how the means of proof must be related to establish its relevance, among other topics, in the same way the powers of the victim are analyzed, with respect to which a criticism of the still limited participation in the substantive issues, on the other hand the nature and importance of the probative discovery is studied and how it operates for each of the parties, the present study is carried out based on the documentary method and from a practical perspective, for this purpose use is made of examples that clarify procedural concepts.
\end{abstract}

\section{Keywords:}

intermediate phase, probative discovery, accusatory court, criminal proceedings

\section{Resumen:}

La etapa intermedia en el proceso penal acusatorio se encuentra constituida por dos fases: la escrita y oral, en este trabajo se aborda la fase escrita, para tal efecto se explica en qué consiste, la importancia y requisitos del escrito de acusación. Se hace especial referencia al principio de congruencia fáctica y su relación con la formulación de imputación y la sentencia. Las formas de autoría y participación y cómo se deben relacionar los medios de prueba para establecer su pertinencia, entre otros tópicos. De igual forma, se analizan las facultades de la víctima, respecto de las cuales se hace una crítica de la aún limitada participación en los temas de fondo. Por otra parte, se estudia la naturaleza e importancia del descubrimiento probatorio y cómo opera para cada una de las partes. El presente ensayo se realiza con base en el método documental y desde una perspectiva práctica, para tal efecto se hace uso de ejemplos que permiten clarificar los conceptos procesales.

\section{Palabras Clave:}

fase intermedia, descubrimiento probatorio, corte acusatorio, proceso penal

\section{Introducción}

La etapa intermedia en el proceso penal de corte acusatorio tiene como objetivo depurar los hechos, el derecho y la prueba que serán objeto de debate en la diversa de juicio, su antecedente es la etapa de investigación, que se divide en investigación inicial y complementaria. En la primera, se recaba información para resolver sobre el ejercicio de la acción penal mediante la formulación de imputación; por el principio de economía procesal, no toda la información que se recaba en la etapa de investigación podrá ser motivo de debate, por ello, la etapa intermedia funciona como un filtro procesal, mediante el cual las partes debaten sobre la prueba que habrá de desahogarse en la etapa de juicio, que incluye las audiencias de debate y de individualización de sanciones.

La etapa intermedia inicia con el escrito de acusación que presenta el fiscal ante el juez de control y concluye con el auto de apertura a juicio oral.

\footnotetext{
a Autor de Correspondencia, Universidad Autónoma del Estado de Hidalgo, Email: javiersanchez_1978@ hotmail.com

b Universidad Autónoma del Estado de Hidalgo, Email: rwzd77@ hotmail.com

c Universidad Autónoma del Estado de Hidalgo, Email: cantemgaona@uaeh.edu.mx
} 
A su vez, la etapa intermedia se divide en la fase escrita y fase oral, la primera inicia con el escrito de acusación y comprende todos los actos previos a la audiencia intermedia y la segunda, comienza con la audiencia intermedia y concluye con el auto de apertura de juicio oral.

En el presente trabajo se aborda el estudio de los actos procesales que van desde el escrito de acusación hasta antes de celebrarse la audiencia intermedia, no se aborda la exclusión de medios de prueba, pues ello corresponde a la fase oral de la etapa intermedia, ni los medios de prueba en particular debido a que su estu di o es propio de la etapa de juicio.

Se hace un análisis del escrito de acusación con una visión práctica de los efectos que tiene el precisar los hechos de la acusación, su clasificación jurídica, la forma de invocar y relacionar los medios de prueba para justificar su pertinencia e idoneidad, la importancia de solicitar el decomiso de bienes, entre otros aspectos.

Las facultades de la víctima u ofendido, el imputado y su defensa se abordan desde un punto de vista pragmático, para que el operador jurídico tenga conocimiento qué, cómo y cuándo realizar determinados actos procesales en defensa de sus derechos o intereses.

En último lugar se realizan algunas reflexiones sobre un tema novedoso en el derecho procesal mexicano: el descubrimiento probatorio, el cual se aborda como instrumento procesal derivado del principio de contradicción en el aspecto relativo a garantizar que las partes conozcan, en la etapa intermedia los registros de investigación y medios de prueba que se incorporarán en la audiencia de debate.

\section{La fase escrita de la etapa intermedia}

\subsection{Acusación}

Cerrada la investigación complementaria, dentro del plazo de quince días hábiles siguientes, el fiscal deberá: formular acusación, solicitar el sobreseimiento o la suspensión del proceso, en este apartado nos ocuparemos del supuesto en el que decide formular acusación.

Con el escrito de acusación se inicia la etapa intermedia, en su fase escrita, el cual tiene por objeto fijar la postu ra del fiscal respecto de los hechos, el derecho y la pru eba que pretende sea materia de la audiencia de juicio; sus requisitos se encuentran previstos en el artículo $335 \mathrm{del}$ Código Nacional de Procedimientos Penales (CNPP), los cuales analizaremos a continuación:

El numeral 335 del CNPP contempla, como requisitos de la acusación: la individualización de los acusados y su defensor, así como la identificación de la víctima, ofendido y su asesor jurídico; esto se cumple con indicar el nombre y domicilio que se tenga registrado para recibir notificaciones; la importancia de incluir estos datos radica en que de ahí se obtiene información para el auto de apertura a juicio oral, que es el único documento que recibe el Tribunal de Enjuiciamiento para la audiencia de debate.

Con relación a los hechos que se contienen en el escrito de acusación, estos deben corresponder a los fijados en el auto de vinculación a proceso, tal como lo establece el penúltimo párrafo del artículo 335 del CNPP, los cuales deben tener congruencia con los hechos invocados en la formulación de imputación en los términos que establece el arábigo 316, penúltimo párrafo, del código adjetivo de la materia.

La identidad de los hechos precisados por el fiscal en la formulación de imputación, los establecidos en el auto de vinculación a proceso y los insertados en la acusación, tienen como finalidad el respeto al principio de congruencia fáctica, también denominado de coherencia o de correlación entre la acusación y la sentencia; reconocido por la Corte Interamericana de Derechos Humanos (CortelDH) como parte fundamental del debido proceso, como se abundará más adelante.

En efecto, desde el punto de vista de la teoría general del proceso, la base de la sentencia es la pretensión, y por ello, debe existir concordancia e identidad entre la petición inicial y la decisión (Valderrama, 2016:16).

La relación clara, precisa, circunstanciada y específica de los hechos atribuidos en modo, tiempo y lugar, así como su clasificación jurídica, es de los requisitos de mayor importancia del escrito de acusación.

Entre los retos que enfrentan los operadores del sistema de justicia penal de corte acusatorio es aprender a trabajar con hechos (Lorenzo, 2012:37), de ahí, que el legislador exija al fiscal, hasta de manera repetitiva, que el hecho enunciado sea fácil de comprender, que se perciba de manera clara y nítida, para lo cual debe utilizarse un lenguaje ciudadano, sin tecnicismos; además, el hecho debe ser específico, esto es, libre de abstracciones para permitir que el hecho atribuido se distinga de otros de similar naturaleza.

En efecto, en lugar de señalar que el sujeto activo se apoderó de la computadora, deberá decir, por ejemplo: el día veinte de enero de dos mil diecisiete, Juan rompió la ventana del domicilio ubicado en avenida Revolución 1020, colonia Centro de esta ciudad, ingresó a dicho domicilio y del área de la sala tomó una computadora marca Sony, modelo 2139 y salió del domicilio por la ventana que momentos antes había roto.

Cuando el Ministerio Público se limita a señalar que el imputado se apoderó de una cosa mueble, el hecho no resulta específico porque no se puede distinguir de otro, las personas se apoderan de las cosas muebles de 
diversas maneras; que sea específico no significa que en todos los casos se deban de establecer con exactitud, la hora, el minuto y el lugar en el que ocurrieron los hechos, lo trascendente es que el hecho se circunscriba de tal manera que el acusado se pueda defender (Lara, 2014: 25).

Para Adrián Polanco (2014: 44), un hecho es: “...el acontecimiento en el plano de la realidad que modifica de modo observable, por medio de los sentidos, los objetos, siempre con una clara relación de causalidad". En los casos de agresión sexual en contra de menores de edad, es común que la víctima no pueda establecer el día y la hora exacta en la que acontecieron los hechos; pero esto no es obstáculo para formular acusación, exigirlo así, equivaldría a negar el acceso a la justicia a uno de los grupos más vulnerables, como son los menores de edad y doblemente vulnerables cuando la víctima es mujer; en estos casos es importante aproximar las fechas en que acontecieron los hechos.

La precisión de los hechos es base fundamental del derecho de defensa, Kai Ambos (2005: 74), señala: "si el principio de igualdad de armas es tomado en serio, debe informarse al imputado desde un comienzo, de manera suficiente y completa -oralmente o por escrito-, sobre los hechos y su significado jurídico, para que no se encuentre en una desventaja informativa irremediable con relación a las autoridades que están a cargo de la investigación".

Cuando la acusación es imprecisa, ambigua, insuficiente, genera en el imputado una desventaja informativa irremediable; sólo hay defensa de aquello que se conoce, lo cual debe ser preciso y circunstanciado; como explica Sancinetti (2001: 48), entre "los institutos que protegen al sujeto de no ser manipulados por difusas consideraciones de justicia, se halla el principio de que la imputación contra él, debe ser precisa y circunstanciada".

El debido proceso se materializa cuando el ciudadano es informado adecuadamente de las acusaciones que existen en su contra, lo cual es indispensable para poder ejercer el derecho de defensa de manera oportuna, puntual y comprensible (Maier, 1999: 559).

Sobre esta base, podemos concluir que la acusación es una forma de garantizar el debido proceso que tiene repercusión de manera inmediata en el derecho de defensa, pues es el conocimiento claro y preciso de los hechos lo que posibilita al imputado, y su defensa establece su correspondiente estrategia (Jauchen, 2005: 360).

En efecto, la perspectiva desde la cual debe observarse la figura que nos ocupa es del derecho de defensa; sobre esta línea de ideas, la Corte Europea de Derechos Humanos en el caso Pélissier y Sassi contra Francia
(1994) señaló: "el derecho a ser informado sobre la naturaleza y la causa de la acusación debe ser considerada a la luz del derecho del imputado de preparar su defensa".

Por otra parte, bajo el principio de imparcialidad, el Tribunal de Enjuiciamiento tiene vedado alterar los hechos motivo de la acusación, de ahí la trascendencia de lo aquí explicado. En este sentido, Montero y Flores (2008: 22), señalan:

...un proceso en el que no se respeta el elemento básico de la impartición de justicia, como es la imparcialidad, no puede en propiedad denominarse proceso: el proceso se identifica de modo esencial con que, ante un tercero, independiente e imparcial comparecen dos partes situadas en pie de igualdad y con plena contradicción, planteando el conflicto para que aquél lo solucione actuando el derecho objetivo.

Jordi Nieva (2013:146), por su parte, sostiene que el hecho de disponer de poderes probatorios para el juez no se contrapone con el principio acusatorio, porque el hecho de practicar prueba de oficio no hace que el juez pierda su imparcialidad, pero lo que hace indudablemente parcial al juez es la disposición sobre el objeto del proceso, porque esa disposición es asunto exclusivo de las partes. De la misma manera, Marien Aguilera (2008:76) coincide al señalar:

...lo propiamente esencial al acusatorio es la necesidad de que alguien distinto del juez sostenga la acción penal para que el proceso penal comience. Esta necesidad se traduce en dos consecuencias consustanciales al proceso acusatorio: $1^{\text {a }}$ no puede haber juicio sin que se formule acusación, y $2^{\underline{a}}$ el juez no puede dictar sentencia respecto de personas distintas de las acusadas o sobre la base de hechos distintos de los acusados.

La acusación debe incluir las modalidades del delito que concu rrieren, que se refiere a indicar si a consideración de la Fiscalía, se actualiza alguna agravante, aten u ante o calificativa; desde el punto de vista de la calificación jurídica, los hechos que actualicen la modalidad deberán estar precisados en el punto anterior, en este apartado únicamente se precisan cuestiones accesorias que pueden atenuar o agravar la pena, pero cuya existen cia no es indispensable para la actualización del delito. Así, el hecho de que en juicio se acredite que la víctima del delito de homicidio, al momento de los hechos, contaba con un instrumento para defenderse, y por ende, no se justifique la calificativa de ventaja, no significa que no exista el delito de homicidio; en todo caso, no se probó la calificativa de ventaja pero sí el delito de homicidio; por ello, las modalidades deben indicarse por separado, dada su accesoriedad con la clasificación principal. La clasificación jurídica en el escrito de acusación no es determinante, porque la misma puede ser variada en los 
alegatos de apertura o de clausura, como así lo dispone el ordinal 398, del CNPP, en cuyo caso para respetar el derecho de defensa, el juzgador que presida la audiencia dará al imputado y a su defensor la oportunidad de expresarse al respecto, y les informará sobre su derecho a pedir la suspensión del debate para ofrecer nuevas pruebas o preparar su intervención.

Así, la única limitante para que el Tribunal de Enjuiciamiento condene por delito diverso al contenido en el escrito de acusación, es que los hechos permanezcan inalterables.

En el caso Fermín Ramírez vs. Guatemala (2005), la CorteIDH, interpretó el artículo 8.2, de la Convención Americana de Derechos Humanos y concluyó que la descripción material de la conducta imputada contiene los datos fácticos recogidos en la acusación; por ende, el imputado tiene derecho a conocer, a través de una descripción clara, detallada y precisa, los hechos que se le imputan; sin embargo, la calificación jurídica de éstos puede ser modificada durante el proceso por el órgano acusador o por el juzgador, sin que ello atente contra el derecho de defensa, cuando se mantengan sin variación los hechos mismos y se observen las garantías procesales previstas en la ley para llevar a cabo la nueva calificación; esto es, que el imputado y su defensa tengan oportunidad de debatir el cambio de clasificación jurídica.

El escrito de acusación fija la litis del debate, por ello, en este documento se debe precisar qué tipo de autoría o participación se atribuye al acusado, para el caso del estado de Hidalgo, en el artículo 16 del Código Penal se enlistan cada una de éstas.

No es el objetivo del presente trabajo abundar en las distintas formas de autoría o participación; sin embargo, para explicar a qué se refiere este requisito que debe cumplir el escrito de acusación, es importante abordar, a grandes rasgos, los supuestos del artículo 16 invocado.

El Código Penal de Hidalgo parte de la premisa de que existen dos formas de intervención en la comisión de un hecho delictivo: autoría y participación; Gustavo Malo Camacho, (2001: 488) indica: "Autoría es la producción del acto propio; en tanto que participación es intervención en la producción del acto ajeno"

El artículo 16 del Código Penal de Hidalgo, establece que son autores: el autor directo, coautor, autor mediato y partícipes, el partícipe inductor, partícipe cómplice y partícipe encubridor.

Existen tres teorías para diferenciar al autor del partícipe: la teoría objetiva del autor, la teoría subjetiva del autor y la teoría final objetiva del dominio del hecho; para la primera, es autor quien realiza los elementos de la conducta típica, así, por ejemplo, si una persona cópula a otra, mientras un tercer sujeto, sostiene las manos de la víctima, quien cópula es autor y quien sostiene las manos de la víctima es partícipe. Para la teoría subjetiva se atiende a si el sujeto quiere o no el acto como suyo, por ejemplo, el sicario que es enviado a privar de la vida a otras personas, sería participe porque no quiere el resultado como suyo.

La teoría mayoritaria es la del dominio del hecho, cuyas soluciones se consideran razonables, pues tienen su base en considerar autor o coautor quien determina el curso causal del hecho (Zaffaroni, Alagia y Slokar, 2006).

Para Claus (2014), la autoría se determina mediante el dominio del hecho, por lo que es autor quien en la realización del delito aparece como personaje central por su influencia determinante 0 decisiva en el acontecimiento.

En este orden de ideas, si en la comisión de un delito la aportación de uno de los que interviene es determinante, tendrá la calidad de autor o coautor, según sea el caso; en cambio, existen tres formas accesorias de intervenir en el delito, que son: inductor, cómplice y encubridor, su principal característica es que no determinan la comisión del hecho delictivo, el inductor es quien determina a otro la comisión de un hecho delictivo, el cómplice es quien presta ayuda a otro para cometer el delito; mientras que el encubridor ayuda al autor o coautor después de haberse ejecutado el delito.

Los Tribunales Colegiados del Poder Judicial de la Federación, al interpretar las formas de intervención en la comisión del delito, han adoptado la teoría del dominio del hecho funcional.

Al respecto se han emitido los siguientes criterios jurisprudenciales:

COAUTORÍA MATERIAL. SE GENERA CUANDO EXISTE ENTRE LOS AGENTES CODOMINIO FUNCIONAL DEL HECHO. Aun cuando la aportación de un sujeto al hecho delictivo no pueda, formalmente, ser considerada como una porción de la acción típica, si aquélla resulta adecuada y esencial al hecho de tal manera que evidencia que existió entre los agentes un reparto del dominio del hecho en la etapa de su realización (codominio funcional del hecho), tal aportación es suficiente para considerar a dicho agente coautor material del delito en términos del artículo 13, fracción III, del Código Penal para el Distrito Federal, como ocurre en el delito de robo, cuando uno de los activos es el que se apodera materialmente de la cosa ajena, mientras otro, amén de brindarle apoyo con su presencia, impide que uno de los ofendidos acuda a solicitar auxilio (Tesis I.10.P. J/5).

COAUTORÍA. SE ACTUALIZA CUANDO VARIAS PERSONAS, EN CONSENSO Y CON CODOMINIO CONJUNTO DEL HECHO, DIVIDIÉNDOSE LAS ACCIONES DELICTIVAS Y MEDIANTE UN PLAN COMÚN ACORDADO ANTES O DURANTE LA PERPETRACIÓN DEL SUCESO, CONCURREN A LA EJECUCIÓN DEL HECHO PUNIBLE (LEGISLACIÓN DEL DISTRITO 
FEDERAL). La figura de la coautoría a que se contrae la fracción II del artículo 22 del Código Penal para el Distrito Federal, se actualiza cuando varias personas en consenso y con codominio conjunto del hecho, dividiéndose las acciones delictivas y mediante un plan común acordado antes o durante la perpetración del suceso, concurren a la ejecución del hecho punible y, por tanto, son responsables en igualdad de condiciones; de ahí que una aportación segmentada, adecuada y esencial al hecho puede bastar para ser considerada y penada como coautoría, aunque formalmente no sea parte de la acción típica, habida cuenta que aquélla se refiere no únicamente a una ejecución compartida de actos que se realizan en sentido objetivo-formal, como porciones pertenecientes a la acción típica, sino a que varios agentes reparten entre sí el dominio del hecho en la etapa de su realización, por lo cual la doctrina ha llamado a esta intervención compartida "codominio funcional del hecho"; sin embargo, esa actuación funcional para convertir al agente como coautor, debe ser necesaria y esencial para la realización del hecho delictivo (Tesis 661).

Como explica Champo (2005: 74), la coautoría exige un previo acuerdo en el que exista división del trabajo funcional y que la aportación en la fase ejecutiva sea un requisito indispensable para la realización del resultado pretendido.

El artículo 19 del Código Penal para el Estado de Hidalgo, amplía las tradicionales formas de autoría y participación, mediante el "delito emergente", por el cual se solidariza a todos los que realizaron un determinado delito si durante su comisión uno de ellos ejecutó uno diferente sin acuerdo previo de los demás (Díaz, 2008: 78).

En la práctica, suele confundirse la coautoría con el delito emergente, su diferencia radica que en aquella existe previo acuerdo y en este no. Por ejemplo, cuando diversas personas acuerdan apoderarse de cosas muebles ajenas y para ello, deciden que uno de los acusados deberá golpear a uno de los vigilantes, lo cual resulta indispensable para ingresar al inmueble, todos responden del resultado de las lesiones, mediante la figura de la coautoría por codominio funcional; de no probarse el acuerdo previo, todos los acusados responderán por las referidas lesiones a título de delito emergente, siempre y cuando se surtan los supuestos del artículo 19, del código citado.

Respecto a los medios de prueba que se pretendan desahogar en la audiencia de juicio, el artículo 335 del CNPP establece una serie de requisitos que deben cumplirse en el ofrecimiento respectivo; en el caso de testigos o peritos deben identificarse adecuadamente, para ello debe invocarse su nombre completo, domicilio, modo de localizarlos y los puntos sobre los que versará su declaración.
La legislación procesal no exige que al ofrecer la prueba pericial se anexen los títulos que acrediten la profesión o especialidad del perito; no obstante, para que el juez de control pueda evaluar la idoneidad del perito; en caso de controversia, es importante que sí se agreguen dichos documentos.

Ahora, la falta de los documentos referidos, por sí solos, no es causa de inadmisión de la prueba pericial, pues en el sistema penal acusatorio los peritos pasan por dos juicios de idoneidad, con propósitos distintos y etapas diversas; el primero de ellos, de admisibilidad, cuya función es evitar el ingreso a juicio de expertos sin una mínima calificación en su área; el segundo, se realiza en la audiencia de juicio y su objeto es pesar su credibilidad; en consecuencia, el análisis de idoneidad es relativamente bajo o preliminar, basta que se acredite que el perito tiene conocimiento especial o experiencia relevante en el área de su experticia. Por ejemplo, en Canadá, el examen de idoneidad considera que el perito está calificado para declarar en un juicio sí adquirió un conocimiento especial o peculiar derivado del estudio o experiencia de los temas sobre los cuales rendirá testimonio. Así, la acreditación de idoneidad dependerá del tipo de experto que se intente presentar y por lo mismo no puede existir una regla rígida en la materia, dado que la legislación procesal admite experticia no solo tratándose de conocimiento científico sino que incorpora la experticia de artes y oficios (Duce y Riego, 2008).

En lo que se refiere a los datos de identificación, esta exigencia está relacionada, con el principio de contradicción, porque tiene como objetivo que las partes conozcan quién es el testigo, incluso si así lo consideran entrevistarlo previo a la audiencia de juicio.

Por otra parte, los puntos sobre los que declarará el perito o testigo tienen como objetivo fijar bases para evaluar la pertinencia de la prueba en la etapa intermedia y la pertinencia de las preguntas en el examen o contra-examen en la audiencia de juicio.

En el escrito de acusación, el agente el Ministerio Público debe fijar sus pretensiones, por ello, el artículo 335 del CNPP determina que se deberá expresar el monto de la reparación de daños y perjuicios y la pena a imponer.

Congruente con lo anterior, la siguiente exigencia es la determinación de los medios de prueba que se pretendan desahogar en la audiencia de individualización de sanciones, en caso de que en la audiencia de debate el fiscal haya obtenido fallo condenatorio.

Nadie puede ser privado de sus bienes sino es mediante juicio. Por ello, es importante que el fiscal desde el escrito de acusación haga la solicitud de decomiso de bienes a efecto de que el acusado tenga la oportu nidad 
de defenderse respecto a dicho tema.

La propuesta de acuerdos probatorios y de terminar el proceso mediante una salida alterna o forma de terminación anticipada no es una obligación a cargo del fiscal; sin embargo, se ha establecido por el legislador como una forma de alentar a las partes a centrar el debate en los temas respecto de los cuales existe controversia o incluso concluir el proceso mediante un acuerdo reparatorio, suspensión condicional del proceso o procedimiento abreviado, con la finalidad de no agotar la etapa de juicio.

\subsection{Facultades de la víctima}

Los derechos de la víctima fueron reconocidos por primera vez, a nivel constitucional, mediante la reforma del 3 de septiembre de 1993, que consistió en agregar un párrafo al final del listado de los derechos de los inculpados; fue la reforma constitucional, publicada en el Diario Oficial de la Federación (DOF) del 21 de septiembre de 2000 , por la cual se agregó el aparto $B$, al artículo 20 constitucional y en cada una de sus fracciones se precisaron los derechos de la víctima, los cuales fueron trasladados al apartado $\mathrm{C}$, precisados y aumentados con la reforma en materia de seguridad y justicia publicada en el DOF el 18 de junio de 2008.

El reconocimiento de los derechos de las víctimas a nivel constitucional es producto de una visión transicional de la justicia, que exige que las víctimas tengan acceso a la justicia, a la verdad y a la reparación del daño (Negrete, Guerrero y Uribe, 2015: 56).

Los derechos de las víctimas en el proceso penal de corte acusatorio, se pueden encausar en los tres ejes precisados en el párrafo anterior.

Entre los derechos de la víctima destaca el de acceso a la justicia, para lo cual debe considerarse que su satisfacción requiere estar conscientes que quien deviene víctima era de su vulnerable frente al delito y su agresor; por lo cual, no debe ser objeto de revictimización por el sistema de justicia penal (Zamora, 2014: 51).

Conforme al artículo 338 del CNPP, presentado el escrito de acusación, se corre traslado a las partes y dentro de los tres días siguientes, la víctima puede hacer uso de las siguientes facultades: constituirse coadyuvante; señalar vicios formales de la acusación, ofrecer medios de prueba y solicitar el pago de la reparación del daño y cuantificar su monto.

Es importante precisar que el artículo 110 del CNPP, reconoce la participación del asesor jurídico, como representante de la víctima, condicionado a que previamente informe lo que promoverá a su representado; de esta manera se respeta el principio de igualdad procesal, pues a diferencia del sistema tradicional en el que se limitaba la participación del asesor jurídico solo para algunos aspectos, en el proceso de corte acusatorio, el asesor jurídico como parte en el proceso, actúa en representación de la víctima u ofendido, así las facultades de la víctima, válidamente puede ejercerlas el asesor jurídico.

La participación de la víctima en el proceso penal acusatorio, es un reflejo de un Estado democrático de derecho; pues el mismo implica participación en términos de igualdad, y ello en la justicia penal supone que los actores del drama penal deben participar, sin importar su posición de víctima, imputado o autoridad, lo cual debe realizarse en un plano equitativo $y$ debidamente equilibrado, lo que significa no solo igualdad de fuerza entre acusados y agraviados, sino también entre estos respecto del Estado (Zamora, 2014: 99).

A continuación, analizaremos las facultades que la víctima puede ejercer durante la fase escrita de la etapa intermedia; en el entendido que el objeto de este estudio no es analizar a profundidad los derechos de la víctima en el proceso penal acusatorio.

Dentro de los tres días siguientes a la notificación de la acusación, la víctima puede solicitar al fiscal que aclare, precise o corrija algún aspecto de la acusación; siempre y cuando se trate de una cuestión de forma. Por ejemplo, que se corrija el nombre de algún testigo o perito, se precise la hora en que se dice que ocurrieron los hechos; entre otros; pero, no podrá solicitar cambios de fondo; esto es, que en lugar de acusar por lesiones, lo haga por el delito de homicidio en grado de tentativa.

Por otra parte, podrá presentar una acusación coadyuvante; pero siempre supeditada a la presentada por el fiscal. Por lo que a diferencia de los que ocurre en sistemas de tradición anglosajona, como en los Estados Unidos, en los que la persecución penal es exclusiva de los fiscales y la víctima no tiene intervención alguna, nuestro sistema, en este aspecto se asemeja al caso de Alemania, en donde la participación de la víctima, en juicio, está subordinada a la acusación del fiscal (Riego, 2014:315).

Entre las razones que se esgrimen para limitar la intervención del juez de control en cuestiones de fon do, es que la persecución de los delitos, desde el punto de vista constitucional corresponde al Ministerio Público, quien requiere de algún margen de discrecionalidad y la intervención del juzgador, al grado de establecer la clasificación jurídica, correcta de acuerdo a su criterio, significaría la afectación al principio acusatorio y derecho de defensa (Rodríguez, 2013: 46).

En el sistema tradicional, la víctima se constituía coadyuvante del Ministerio Púbico, mediante un escrito en el que bastaba que hiciera tal manifestación. En el proceso de corte acusatorio debe recordarse que la víctima $u$ ofendido es parte del proceso penal y la 
facultad a la que se refiere el ordinal 338, fracción I, del CNPP, es a constituirse coadyuvante del proceso.

Ahora, si la victima decide hacer uso de la citada facultad, deberá presentar un escrito que reúna los requisitos a que se refiere el numeral 335 del CNPP; es decir, deberá con las mismas exigencias del fiscal, formular acusación.

En el supuesto de que la víctima manifieste que comparece a constituirse coadyuvante, pero si su escrito no reúne los requisitos del artículo 335 invocado, el juez de control no podrá tener por constituida como coadyuvante del proceso a la víctima $u$ ofendido, pues la defensa no estaría en posibilidades de contestar la acusación coadyuvante; lo cual le impide defenderse.

Con relación a las consecuencias de no constituirse coadyuvante del proceso, consideramos que ello únicamente implica que la víctima no pueda formular alegatos de apertura y clausura, pues al no existir acusación adyacente, no existe teoría del caso que exponer.

Contrario a lo que en la práctica se ha llegado a sostener por algunos litigantes, la falta de acusación coadyuvante no priva a la víctima $u$ ofendido de la facultad de examinar o contra examinar, por sí o por conducto del asesor jurídico a testigos y peritos, pues no haber presentado acusación, no significa que haya dejado de ser parte en el proceso.

En otro orden de ideas, la víctima u ofendido podrá únicamente ofrecer medios de prueba para completar la acusación del fiscal, en cuyo caso, deberá verificar que sus medios de prueba sean pertinentes con relación a la teoría del caso de la fiscalía; esta facultad tiene como objetivo garantizar el derecho de acceso a la justicia de la víctima, pues para el caso de que el fiscal haya omitido ofrecer algún medio de prueba para la audiencia de debate, la víctima aún puede realizarlo.

En último lugar, la víctima puede circunscribirse a solicitar el pago de la reparación del daño y cuantificar su monto, en cuyo caso podrá ofrecer medios de prueba para tal efecto.

En este sentido, los principios y directrices básicos sobre el derecho de las víctimas de violaciones manifiestas de las normas internacionales de derechos humanos y graves del derecho internacional humanitario a interponer recursos y obtener reparaciones, establece como criterios rectores para una plena y efectiva reparación del daño, no solo para el caso de graves violaciones a derechos humanos, sino para la reparación en general, la restitución, lo cual significa que habrá de devolver a la víctima a la situación anterior a la violación; la indemnización por los daños y perjuicios económicamente evaluables, de manera apropiada y proporcional, tales como el daño, físico o mental, pérdida de oportunidades, perjuicios morales, gastos de asistencia jurídica, entre otros; rehabilitación, que ha de incluir la atención médica o psicológica; la satisfacción, que de ser procedente implica la revelación pública de la verdad, entre otras, además de garantías de no repetición, que han de incluir medidas y mecanismos destinados a prevenir que la conducta se vuelva a repetir (Zamora, 2014: 117).

Aunque la víctima no haga uso de esta facultad, el juzgador no podrá absolver de la reparación del daño si ha emitido sentencia condenatoria, incluso de no haberse cuantificado su monto, esto será motivo de ejecución de sentencia.

Así lo ha resuelto el Segundo Tribunal Colegiado en Materia Penal del Primer Circuito, en la siguiente tesis: REPARACIÓN DEL DAÑO A LA VÍCTIMA EN UN PROCESO PENAL. EL JUZGADOR DEBE CONDENAR POR ESE CONCEPTO CUANDO SE ACREDITEN EL DELITO Y LA RESPONSABILIDAD PENAL, AUNQUE LAS PARTES NO LO HUBIEREN SOLICITADO, SIN PERJUICIO DE DEJAR PARA LA VÍA INCIDENTAL LA CUANTIFICACIÓN DE SU MONTO. Conforme al artículo 20, apartado C, fracción IV, de la Constitución Política de los Estados Unidos Mexicanos, en relación con los diversos 45 del Código Penal para el Distrito Federal, aplicable para la Ciudad de México, y 12, fracción II, de la Ley General de Víctimas, la autoridad ministerial, derivado de la comisión de un delito, debe solicitar la reparación del daño de forma expedita, proporcional, justa, oportuna, plena e integral y, a su vez, el juzgador condenar al enjuiciado a ese concepto cuando haya emitido sentencia condenatoria. Para acreditar su procedencia, es necesario demostrar los mismos elementos de la responsabilidad civil extracontractual: el hecho ilícito, el daño y el nexo causal entre éstos. En materia penal, estos elementos se encuentran determinados por la existencia del delito y la responsabilidad penal, por lo que al probarse el delito, también puede considerarse acreditado el hecho ilícito generador de la responsabilidad civil. Ahora bien, aunque es cierto que, por regla general, el daño debe ser probado, es legal considerar que las personas que tienen el carácter de víctimas han resentido alguna afectación, pues esa posición, por sí misma, implica que han sufrido un daño a consecuencia de la conducta tipificada como delito, como lesiones transitorias o permanentes que impliquen la pérdida o disminución de sus facultades físicas o mentales, entre otras. Por estos motivos, el legislador evitó a la víctima la necesidad de instaurar un juicio civil para reparar los daños y perjuicios y, en su lugar, hacerlo simultáneamente en la sentencia penal, en cuyo juicio de origen, en todo caso, sólo debe acreditarse la intensidad del daño, pero no su existencia, por lo que no debe confundirse ésta con la cuantificación de su indemnización. Bajo esta óptica, es 
innecesario que expresamente se reclame por las partes la reparación del daño por la comisión de un delito para que se actualice la obligación del Juez, como rector del proceso, de imponer la condena a su pago cuando haya dictado una sentencia condenatoria al enjuiciado, pues el deber constitucional de la autoridad a este respecto es independiente de que la víctima haya formulado o no agravios en este sentido. Por tanto, si se dicta sentencia condenatoria por estimarse acreditados el delito y la responsabilidad penal del sentenciado en su comisión, el Juez debe condenar a la reparación del daño, sin perjuicio de dejar para la vía incidental la cuantificación de su monto, si en el sumario no existen elementos de convicción suficientes para ello (Tesis 2o.P.62 P).

\subsection{Facultades de la defensa}

Una vez que la víctima u ofendido ha hecho uso de las facultades que hemos precisado en el apartado an terior o que exista constancia de que ha transcurrido el plazo concedido sin que se haya hecho uso de tales facultades, se le concederá al acusado y a su defensor un plazo de diez días hábiles para que, mediante escrito hagan uso de alguno de los siguientes derechos: Solicitar la corrección de vicios formales de la acusación, que son todos aquellos que no modifican el fondo de la acusación y sólo refieren aspectos imprecisos, ambiguos y oscuros de la acusación en cuanto a requisitos que pueden corregirse (González, 2017: 175).

En otras palabras, se trata de aspectos que puedan ser subsanables, como lo es: indicar la hora en que ocurrieron los hechos, el lugar, o el nombre correcto de algún testigo, víctima o imputado o el domicilio donde se puede localizar al testigo o perito; es importante que en ningún caso podrá tildarse de vicio formal la falta de comprobación de los hechos motivo de la acusación, esto en todo caso, sería una cuestión de fondo, motivo de discusión en la audiencia de debate, el juez de control por ningún motivo debe permitir que se aleguen cuestiones de fondo.

Por otra parte, es en este plazo, en el que mediante escrito pueden ofrecerse los medios de prueba que la defensa o acusado pretendan desahogar en la audiencia de debate.

La consecuencia de no ofrecer medios de prueba en este plazo implica que las mismas sean excluidas en la fase oral de la etapa intermedia.

Lo anterior tiene su fundamento en el principio de contradicción e igualdad procesal, pues la antelación con la cual deben ofrecerse los medios de prueba tiene como objetivo que las partes tengan la oportunidad de rebatir o contradecir dichas pruebas para restarles eficacia y valor probatorio; sin que ello contravenga los principios de seguridad jurídica, tutela judicial efectiva y defensa adecuada, pues la exclusión de pruebas, no implica la denegación de justicia, ya que si bien ello es desfavorable para el imputado, no significa que lo deje en estado de indefensión, puesto que deben cumplirse ciertas formalidades en el procedimiento, en el caso, lo relativo a los plazos para ofrecer pruebas.

Es en este sentido que se ha decantado el siguiente criterio:

OFRECIMIENTO DE MEDIOS DE PRUEBA EN EL SISTEMA PENAL ACUSATORIO. EL QUE REALIZA EL IMPUTADO RESPECTO DE AQUELLOS QUE PRETENDA DESAHOGAR EN JUICIO ORAL, DEBE FORMULARLO EN LA FASE ESCRITA DE LA ETAPA INTERMEDIA DENTRO DE LOS DIEZ DÍAS SIGUIENTES A QUE FENEZCA EL PLAZO A QUE SE REFIERE EL ARTÍCULO 340, PÁRRAFO PRIMERO, DEL CÓDIGO NACIONAL DE PROCEDIMIENTOS PENALES PUES, DE LO CONTRARIO, DEBEN EXCLUIRSE. EI artículo 334 del Código Nacional de Procedimientos Penales establece que la etapa intermedia tiene por objeto el ofrecimiento y admisión de los medios de prueba, así como la depuración de los hechos controvertidos que serán materia del juicio, y se compondrá de dos fases, una escrita y otra oral. En la primera, se lleva a cabo el ofrecimiento de los medios de prueba, esto es, por escrito ante el Juez de control en términos del artículo 340 de dicho ordenamiento. Por su parte, el diverso artículo 337 regula el descubrimiento probatorio, que consiste en la obligación del imputado o defensor de entregar materialmente copia de los registros al Ministerio Público y acceso a las evidencias materiales que ofrecerá en audiencia intermedia; así como que el acusado o su defensor deberá descubrir los medios de prueba que pretenda ofrecer en la audiencia de juicio; de ahí que el imputado debe ofrecer los medios de prueba que pretenda desahogar en el juicio oral en el plazo de diez días siguientes a que fenezca el señalado para la solicitud de coadyuvancia de la víctima $u$ ofendido, a que se refiere el primer párrafo del citado numeral 340, ya que de no hacerlo así, deben excluirse, pues brindar la posibilidad de ofrecer los medios de prueba como lo pretenden el imputado y su defensor, esto es, con base en el último párrafo del artículo 337, que dispone que en caso de que éstos requieran más tiempo para preparar el descubrimiento o su caso, podrán solicitar al Juez de control, antes de celebrarse la audiencia intermedia o en la misma audiencia, que les conceda un plazo razonable y justificado para tales efectos, se le daría un trato procesal diferente al órgano acusador y a la parte ofendida, lo cual está prohibido por el principio de igualdad procesal que impera en el sistema procesal penal acusatorio y oral; máxime que se perdería de vista que el ofrecimiento de medios de prueba y el 
descubrimiento probatorio son momentos procesales diversos, porque en la primera fase de la etapa intermedia es donde se lleva a cabo ese ofrecimiento, lo que es diferente a lo previsto en el diverso 337 indicado, es decir, el descubrimiento probatorio, mismo que deberán realizar las partes procesales durante la celebración de la audiencia intermedia, una vez que ya fueron ofrecidos esos medios ante la autoridad jurisdiccional en sus respectivas contestaciones a la acusación planteada por el Ministerio Público. Por tanto, aun cuando existe un margen de ofrecimiento y admisión de medios de prueba, la revisión sobre su incorporación debe ser puntual y estricta, esto es, debe sujetarse a los presupuestos procesales que rigen la función jurisdiccional, dentro de los cuales están los plazos inscritos en la ley, por lo que las partes deben sujetarse a las formalidades que al respecto establece la legislación aplicable (Tesis: I.9o.P.252 $P, 10 a$.

El CNPP no señala los requisitos que debe reunir el ofrecimiento de medios de prueba por parte de la defensa; sin embargo, el artículo 10 del ordenamiento antes citado establece que todas las personas que intervengan en el procedimiento penal tendrán las mismas oportunidades para sostener la acusación o defensa, en consecuencia, se considera que debe aplicarse lo dispuesto en el último párrafo en el artículo 335 del CNPP; es decir, así como el fiscal debe presentar una lista identificando testigos o peritos, con nombre, apellidos, domicilio y modo de localizarlos, los puntos sobre los que serán interrogados; la defensa al ofrecer medios de prueba, debe cumplir con esta misma obligación.

Lo anterior a efecto de respetar los principios de contradicción, lealtad y objetividad; para que el fiscal tenga la posibilidad de ubicar a los testigos y en su caso interrogarlos; de igual manera, la defensa debe de precisar los puntos sobre los que versará la declaración del testigo, para que en su momento el fiscal pueda objetar las preguntas que resulten impertinentes e incluso evaluar la sobreabundancia de medios de prueba (Jauchen, 2015: 240).

La circunstancia de que el legislador no haya precisado los requisitos que debe reunir el ofrecimiento de pruebas de la defensa no significa que el derecho de defensa es ilimitado, aceptar esto implicaría que en juicio se pueden desahogar pruebas impertinentes o sobreabundantes, retardando con ello la administración de justicia pronta y expedita, cuya tutela se inspira en el artículo 17 constitucional.

Es en esta etapa procesal en la que la defensa puede plantear que dos o más procesos se acumulen o diversos procesos tramitados en una misma causa penal, se separen.
La acumulación de procesos acontece en los siguientes supuestos:

Que exista concurso de delitos, esto es que con una o más conductas se lesionen dos o más bienes jurídicamente tutelados; cuando es una sola conducta la que produce diversos resultados se trata de un concurso ideal o formal; cuando diversas conductas producen diversos resultados se trata de un concurso real o material.

Respecto del concurso material o real es fundamental que las diversas conductas se den en la misma secuela delictiva; esto es, no en todos los casos en los que se producen diversas afectaciones a bienes jurídicamente tutelados distintos, necesariamente existe concurso real; veamos un ejemplo: una persona en diversas fechas ingresa a distintos domicilios y se apodera de bienes muebles ajenos, en este caso, cuando no existe vín cu lo entre cada uno de estos hechos, se trata de delitos distintos cuya consecuencia es sumar las penas impuestas, porque cada uno de los hechos se dio en secuela delictiva diversa; en cambio, si la persona ingresa a un inmueble y mediante diversas conductas se apodera de bienes muebles ajenos y para ello causa daño al bien inmueble se trata de un concurso material, porque la secuela delictiva es la misma.

Por regla general, es el concurso de delitos lo que actualiza el supuesto de acumulación de procesos, desahogar pruebas de robos que acontecieron en distintas fechas y que no tienen ninguna relación entre sí, haría sumamente compleja la audiencia de debate ante la mezcla de versiones que proporcionarán los testigos sobre hechos diversos, es bajo esta perspectiva mediante la cual debe analizarse la acumulación de procesos.

La conexidad de delitos es otro supuesto que justifica la acumulación de procesos, su esencia, como en el supuesto anterior es evitar resoluciones contradictorias, esta figura se actualiza cuando existe un acuerdo entre diversas personas para realizar conductas de manera simultánea o en diversos tiempos, para cometer un delito, procurar los medios para cometer otro, facilitar su ejecución o asegurar la impunidad.

Es claro que, en estos casos, llevar un proceso por cada uno de los imputados conllevaría a la posibilidad de emitir soluciones contradictorias, incluso afectar el principio de igualdad, porque el imputado, que es juzgado en el primer proceso, tendría desventaja respecto de los demás imputados juzgados por esos mismos hechos pues estos ya conocerían la estrategia de la Fiscalía.

La fracción III del artículo 30 del CNPP establece como causa de acumulación que los procesos se sigan en contra de autores o partícipes de un mismo delito, la diferencia con la conexidad es que en ésta se puede 
tratar de autores de diversos delitos y son los delitos los que se encuentran conexos y ameritan ser juzgados todos en un mismo proceso; esto es, en una misma audiencia de debate.

El último supuesto de acumulación, es cuando se investiga un delito en el que son diversas víctimas; en este caso, se protege el principio de seguridad jurídica a fin de que las víctimas no obtengan resoluciones contradictorias.

La separación de proceso se encuentra regulada en el artículo 35 del CNPP y tiene como requisitos que lo solicite alguna de las partes, y el juez de control considere que de continuar con la acumulación el proceso se demoraría; es decir, en este caso el juez debe ponderar entre el derecho de acceso a la justicia de manera pronta y expedita y el principio de seguridad jurídica en lo relativo a evitar resoluciones contradictorias. En este sentido, es indispensable analizar caso por caso, de tal manera que, si por ejemplo, uno de los imputados se encuentra en espera de que se resuelva un juicio de amparo indirecto en contra del auto de vinculación o auto de apertura a juicio oral; mientras que otro de los imputados exige que le sea dictada sentencia en plazos que contempla en artículo 20 constitucional, es posible que se separen los procesos a efecto de privilegiar el dictado de la sentencia en los plazos contemplados constitucionalmente.

A diferencia de la acumulación de proceso, que debe promoverse antes de dictado el auto de apertura a juicio oral, la separación de procesos puede plantearse hasta antes de la audiencia de juicio, la razón por la cual sea así, es porque en el dictado del auto de apertura a juicio oral, aún existe la posibilidad que alguno de los imputados haga valer recursos ordinarios y en su caso extra ordinarios en contra de dicha resolución, lo que haría retrasar la audiencia de debate respecto a todos los imputados y para que ello no ocurra, es posible que alguno de los acusados, dictado el auto de apertura a juicio oral, solicite la separación de procesos, por la razones que ya hemos explicado.

En el escrito de contestación a la acusación, el imputado o su defensor podrán pronunciarse respecto a la aceptación o no de los acuerdos probatorios, el objetivo de esta disposición es incentivar que las partes centren el debate de la audiencia de juicio en los aspectos realmente controvertidos.

\subsection{Descubrimiento probatorio}

El descubrimiento probatorio tiene su base en el principio de contradicción reconocido en el artículo 20, constitucional, párrafo primero y 6 del CNPP, mediante el cual se tutela el derecho a las partes de conocer los medios de prueba, como un presupuesto básico para estar en posibilidades de controvertirlos y confrontarlos, en un plano de igualdad, de ahí que ningún medio de prueba conocido en la etapa de investigación podrá ser admitido y por ende desahogado en la audiencia de juicio, si previamente las partes no tuvieron oportun idad de conocer el registro y medio de prueba; es decir, las partes deben tener oportunidad no solo de conocer la información que se pretende llevar a juicio sino también de recabar medios de prueba para estar en posibilidades de demostrar la falta de credibilidad del medio de prueba.

El artículo 337 del CNPP dispone que, el descubrimiento probatorio sea la obligación que tienen las partes de darse a conocer los medios de prueba que pretendan desahogar en la audiencia de juicio.

Aunque se trata de la misma obligación, que debe cumplir tanto el fiscal como la defensa, la forma en que se cumple es diferente; en efecto, tratándose del fiscal dicha obligación surge a partir de que el imputado: a) se encuentre detenido, b) sea citado a declarar; o c) sea objeto de un acto de molestia y se pretenda recibir su entrevista, tal como lo establece el artículo 218 del CNPP.

La regla general en la etapa de investigación inicial es que los registros, documentos y cosas relacionadas con la investigación sean reservadas, y solo cuando se actualiza alguna de las hipótesis señaladas en el párrafo anterior inicia la obligación del Ministerio Público, de permitir a la defensa e imputado, el acceso a dichos registros.

En este orden de ideas, la decisión del fiscal de citar al imputado a declarar durante la investigación debe ser estratégica, porque a partir de dicho momento, el imputado tendrá el derecho de conocer paso a paso el desarrollo de la investigación, lo que incluso podría generar que el imputado obstruya la investigación. Por ello, deben evaluarse los beneficios que se podrían obtener con la solicitud de comparecencia del imputado para declarar y los daños que a la investigación esto podría traer, para lo cual debe partirse de la premisa de que el imputado no podrá ser obligado a declarar.

La reserva de la investigación es una herramienta procesal que permite al fiscal recabar información sin que el imputado o su defensa conozcan su contenido; entre sus objetivos se encuentran garantizar que no se obstruya la investigación.

En el supuesto de que el imputado se encuentre detenido y el fiscal considere que determinados actos de investigación deben mantenerse en reserva por considerar que de enterarse el imputado podría obstaculizar la obtención de información relevante para el esclarecimiento de los hechos, o se tema su destrucción, alteración u ocultamiento; intimidación, amenaza o influencia a los testigos del hecho, para 
asegurar el éxito de la investigación, o para garantizar la protección de personas o bienes jurídicos, el juez de control podrá autorizar su reserva, para lo cual el fiscal en audiencia privada expondrá las razones que actualicen alguna de estas excepciones.

Aunque el CNPP no establece la forma en que se celebrará esta audiencia, consideramos que debe celebrarse a puerta cerrada con la única presencia del fiscal y en su caso, ofendido y asesor jurídico, de no ser así, carecería de sentido autorizar la reserva de actos de investigación si en el debate sobre la autorización judicial, el imputado ha tenido la oportunidad de enterarse.

La reserva de actos de investigación autorizada por el juez de control no podrá prologarse después de la formulación de la acusación.

El Ministerio Público cumple con esta obligación con el hecho de permitir el acceso y copia de todos los registros de investigación.

La violación al descubrimiento probatorio continuo y permanente por el Ministerio Público acontece cuando deja de glosar a la carpeta de investigación los registros de investigación que va recabando. Sin embargo, en tal caso, la defensa debe demostrar tal violación. Por ejemplo, en el caso de que el Ministerio Público haya solicitado la intervención de algún perito para la emisión de una opinión en alguna área de la ciencia o arte, y no se haya glosado el informe pericial a la carpeta de investigación, no obstante que el perito haya manifestado haber remitido el correspondiente informe $y$ que por negligencia o dolo éste no se haya agregado a la carpeta de investigación, en este caso existiría una violación al descubrimiento probatorio y por ende, al principio de contradicción.

En el caso de la víctima u ofendido, como lo establece el segundo párrafo del artículo 337 del CNPP, notificada de la acusación presentada por el Ministerio Público, dentro del plazo de tres días hábiles además, de constituirse coadyuvante, señalar vicios formales $u$ ofrecer medios de pruebas; en este último supuesto deberá cumplir con el descubrimiento probatorio, esto es, entregar a la defensa, imputado y Ministerio Público copia de los registros y acceso a los medios de prueba, que pretenda desahogar en la audiencia de juicio.

En el caso de la defensa, dentro del plazo de diez días hábiles contados a partir de que haya fenecido en plazo concedido a la víctima para que se constituya coadyuvante del proceso, deberá entregar al Ministerio Público, víctima u ofendido y asesor jurídico, en su caso, copia de los registros y permitir el acceso a los medios de prueba que pretenda desahogar en la audiencia de juicio.

Como puede advertirse, según lo establece el artículo 337 del CNPP. no existirá un auto o resolución mediante el cual se notifique a la defensa la fecha a partir de la cual comenzará a correr el plazo para que cumpla el descubrimiento probatorio, pues, en el caso de que la víctima no se constituya acusador coadyuvante, transcurrido el plazo de tres días hábiles concedido para tal efecto, empezará correr el plazo de 10 días hábiles de la defensa para cumplir con el descubrimiento probatorio.

Con relación a este tópico, Zeferín (2016:179-180) propone realizar una interpretación correctiva en los siguientes términos:

...Dicho de otra manera, si por ejemplo, un acusado ejerce el derecho previsto en el artículo $340 \mathrm{y}$, entre otros aspectos, anuncia en ese mismo escrito los medios de prueba que llevará a juicio, en el día nueve de diez que tiene para ello, o más drásticamente, faltando una hora para que venzan esos diez días, la institución ministerial tendría sólo esa hora para poder acceder a esos medios de prueba, lo que evidentemente sería desproporcional y violaría derechos de igualdad de las partes, ya que el Ministerio Público habría estado descubriendo todos los medios de prueba desde que el acusado fue llamado a entrevista en la etapa de investigación inicial y, en contrapartida, el fiscal sólo tendría un terminó absurdo que redundaría en una imposibilidad material para ejercer sus pretensiones procesales. Lo mismo acontecería con la víctima u ofendido, esto es, en el caso de que anunciara esos medios de prueba a la defensa en el último día que tuviera para ello o en el momento mismo en que está por culminar, se traduciría en imposibilidad de la defensa para acceder a ellos.

De esa manera, se tiene que realizar una interpretación correctiva al respecto; lo anterior, para el efecto de que la operatividad del sistema penal acusatorio no se haga nugatoria ante espacios temporales que resultaran ilusorios. Por esa razón, es que los plazos establecidos en los artículos 338 y 340 no deben ser interpretados como uno solo que conlleve dos efectos (anuncio y descubrimiento simultáneos), sino más bien como un término genérico a seguir. Dicho en otras palabras: los tres y diez días se tendrán que respetar en su integridad por el juez de control, a fin de que tanto la víctima como el acusado hagan valer por escrito los derechos plasmados en tales preceptos. Luego, ya una vez que aquellos sujetos procesales hicieron valer esas prerrogativas, entonces se deberán computar nuevamente esos plazos, esto es, tres y diez, para el efecto de que lleven a cabo su descubrimiento probatorio a las demás partes. Con ello además se tutelaría el equilibrio procesal, ya que la institución ministerial tendría 
un espacio temporal razonable para acceder a los medios de prueba de la defensa y ésta, a su vez, tendría la misma prerrogativa con relación a los aportados por la víctima u ofendido.

\section{Conclusiones}

Lo expuesto en este ensayo permite arribar de manera preliminar a las siguientes conclusiones:

La fase escrita de la etapa intermedia en el proceso penal acusatorio constituye la preparación de la audiencia intermedia, la cual tiene por objeto delimitar los hechos, derecho y prueba, objeto del juicio, a través del auto de apertura a juicio oral.

El proceso penal de corte acusatorio reconoce el derecho de la víctima de acceso a la justicia, mediante la facultad de ofrecer medios de prueba y señalar vicios formales de la acusación. Sin embargo, se limita respecto a la clasificación jurídica. Es importante analizar la conveniencia de que la víctima pueda someter ante el juez de control, la decisión clasificar jurídicamente los hechos motivo de la acusación o bien reconocer la facultad de la victima de plantear ante el Tribunal de Enjuiciamiento una clasificación distinta a la sostenida por el fiscal, con lo cual quedarían incólumes los principios de igualdad, imparcialidad y acceso a la justicia.

El descubrimiento probatorio encuentra asidero en el principio de contradicción, razón por la cual, el fiscal se encuentra obligado a permitir el acceso a los actos de investigación, salvo que por estrategia decida solicitar la reserva de actos de investigación. Sin embargo, no debe ocultarse información sin autorización judicial, pues dicha violación procesal podría violar el derecho de defensa de manera irreparable, cuyos efectos deben ser analizados con detenimiento.

Finalmente, señalamos que los planteamientos realizados en este ensayo son la base de posteriores estudios respecto de aspectos específicos, como son, los efectos de la violación al descubrimiento probatorio y las facultades de la víctima con relación a la clasificación jurídica en la acusación realizada por el fiscal.

\section{REFERENCIAS}

Aguilera Morales, Marien (2008) "Regla de exclusión y acusatorio", en Bachmaier, Lorena (coord.), Proceso penal y sistemas acusatorios. Madrid: Marcial Pons.

Ambos, Kai (2005) Principios de proceso penal europeo. Análisis de la Convención Europea de Derechos Humanos. Colombia: Universidad Externa de Colombia.

Champo Sánchez, Nimrod Mihael (2005) El dominio del hecho. Formas de autoría en el delito. Ciudad de México, México: Porrúa.
Código Nacional de Procedimientos Penales, última reforma 17 de junio de 2016, Diario Oficial de la Federación.

Codigo Penal para el Estado de Hidalgo, última reforma 31 de diciembre de 2019, Periódico Oficial del Estado de Hidalgo.

Díaz Aranda, Enrique (2008) "Introducción a la autoría y participación en el Derecho Penal mexicano" en Homenaje a Ricardo Franco Guzmán 50 años de vida aca démica.pp. 131 158. Ciudad de México, México: Instituto Nacional de Ciencias Penales.

Duce, J. Mauricio y Riego, Christian (2007) Proceso Penal. Santiago, Chile: Editorial Jurídica de Chile.

Fermín Ramírez vs. Guatemala (2005), Corte Interamericana de Derechos Humanos.

González Rodríguez, Patricia Lucila (2017) Manual de derecho procesal penal. Principios, derechos y reglas. Ciudad de México, México: Fondo de Cultura Económica.

Jauchen, Eduardo (2005). Derechos del imputado. Buenos Aires: Rubinzal-Culzoni, 2005.

Jauchen, Eeduardo (2015) Proceso penal. Sistema acusatorio adversarial. Buenos Aires, Argentina: Rubinzal-Culzoni.

Lara, Héctor (2014) La etapa intermedia en el proceso penal acusatorio. Barcelona: Bosch.

Lorenzo, Leticia (2012) Manual de litigación. Buenos Aires: Didot.

Maier, Julio (1999) Derecho Procesal Penal, Fundamentos. Buenos Aires: Editores del Puerto.

Malo, Gustavo (2001) Derecho penal mexicano. México: Porrúa.

Montero Aorca, Juan y Flores Maties, José (2008). Administración de Justicia. Valencia (España): Tirand.

Negrete, Alejandra Guerrero, Arturo y Uribe, David Ricardo (2015) "Los derechos de la víctima en el proceso penalmexicano" en Nova Iustitia. pp. 44-87. México: Poder Judicial de la Ciudad de México.

Nieva Fenoll, Jordi (2013) La duda en el proceso penal. Madrid: Marcial Pons.

Nores, Cafferata (1998) La prueba en el proceso penal. Argentina: Depalma.

Pélissier vs Sassi contra Francia (1994), Corte Europea de Derechos Humanos.

http://www.trastornosmenta lesyjusticiapenal.com/wpcontent/uploads/2-Sentencia-del-Tribunal-Europeo-deDerechos-Humanos-de-25-de-marzo-de-1999-Caso-Pelissiery-Sassi.pdf

Polanco, Adrián (2014) "Los hechos en el derecho procesal" en Pensamiento y Poder. pp. 39-55. Colombia: Corporación Universitaria Remington.

Riego, Christian (2014) “La expansión de las facultades de la víctima en la reforma procesal penal y con posterioridad a ella" en Política criminal. Vol. 9, Núm. 18, pp. 668-690. Chile: Universidad de Talca.

Rodríguez, Manuel (2013) "Sistema acusatorio de justicia penal y principio de obligatoriedad de la acción penal" en Revista de derecho de la Pontificia Universidad Católica de Valparaiso. pp. 643-686. Chile: Pontificia Universidad Católica de Valparaíso.

Roxin, Claus (2014) Derecho penal parte general tomo II. Especiales formas de aparición del delito. España: Civitas.

Sancinetti, Manuel (2001) La nulidad de la acusación por indeterminación del hecho y el concepto de investigación. Buenos Aires: Ad-Hoc. 
Tesis 2o. P.62 P (10a.), Semanario Judicial de la Federación y su Gaceta. Décima Época, t. III, 2018, p. 2477.

Tesis 661, Semanario Judicial de la Federación y su Gaceta. Novena Época,t. III, 2011, p. 616.

Tesis I.1o.P. J/5, Semanario Judicial de la Federación y su Gaceta. Novena Época, t. IV, agosto de 1997, p. 487.

Tesis I.9o.P.252 P (10a.) Semanario Judicial de la Federación y su Gaceta. Décima Época,t. III, septiembre de 2019, p. 2039.

Valderrama, Iván. Dario (2016) "El principio de congruencia en el proceso penal" en Via Invendi et Iudicandi. pp. 159-180. Bogotá: Universidad Santo Tomás.

Zaffaroni, Eugenio Raúl, Alagia, Alejandro y Slokar, Alejandro (2006). Manual de derecho penal. Parte general. Buenos Aires, Argentina: Ediar.

Zamora Grant, José (2006) La víctima en el nuevo proceso penal acusatorio. México: UNAM

Zeferín, Iván. Aarón (2016) "Etapa intermedia y el camino procesal de la prueba" en Código Nacional de Procedimientos Penales. En perspectiva. Reflexiones desde la judicatura. pp. 173-224. Ciudad de México, México: Poder Judicial de la Federación. 